\title{
Wound care in the geriatric client
}

This article was published in the following Dove Press journal:

Clinical Interventions in Aging

8 June 2009

Number of times this article has been viewed

\section{Steve Gist \\ Iris Tio-Matos \\ Sharon Falzgraf \\ Shirley Cameron \\ Michael Beebe \\ Geriatrics and Extended Care Programs, VA Puget Sound Health Care Systems, American Lake Division, Tacoma, WA, USA}

Correspondence: Michael Beebe Integrated Geriatric Programs, VA Puget Sound Health Care Systems, USA

Tel +1 2535832085

Fax +1 2535894133

Email michael.beebe@va.gov
Abstract: With our aging population, chronic diseases that compromise skin integrity such as diabetes, peripheral vascular disease (venous hypertension, arterial insufficiency) are becoming increasingly common. Skin breakdown with ulcer and chronic wound formation is a frequent consequence of these diseases. Types of ulcers include pressure ulcers, vascular ulcers (arterial and venous hypertension), and neuropathic ulcers. Treatment of these ulcers involves recognizing the four stages of healing: coagulation, inflammation, proliferation, and maturation. Chronic wounds are frequently stalled in the inflammatory stage. Moving past the inflammation stage requires considering the bacterial burden, necrotic tissue, and moisture balance of the wound being treated. Bacterial overgrowth or infection needs to be treated with topical or systemic agents. In most cases, necrotic tissue needs to be debrided and moisture balance needs to be addressed by wetting dry tissue and drying wet tissue. Special dressings have been developed to accomplish these tasks. They include films, hydrocolloids, hydrogel dressings, foams, hydrofibers, composite and alginate dressings.

Keywords: wound care, pressure ulcers, vascular ulcers, diabetic ulcers, debridement, elderly

\section{Introduction}

The demographic reality in the United States and other developed countries is that the population is aging and the medical community must provide care for an everincreasing number of elderly individuals. As with other disease processes common in the geriatric population, the incidence of chronic ulcers related to diabetes, peripheral vascular disease, and mobility issues occurs with increasing frequency. The purpose of this article is to address the etiology, assessment, and treatment options for the most frequently encountered types of chronic skin breakdown. Although the original goal may be complete wound healing, palliation and achieving a manageable, chronic wound may be an acceptable outcome.

Approximately $70 \%$ of all pressure ulcers occur in the geriatric population. Their skin has a decrease in water content, tensile strength, and junctional integrity between the dermis and the epidermis. Atrophy of the apocrine and sebaceous glands causes drying of the skin. A loss of subcutaneous tissue, vascularity, and diminishing stability of small blood vessels add other factors to compromise skin integrity. ${ }^{1-3}$

The most common wounds to be discussed are pressure ulcers (decubitus ulcers or bedsores), vascular ulcers (arterial and venous), and neuropathic ulcers. Assessment tools and techniques, appropriate classification systems, dressing choices, and treatment modalities will be addressed. A brief discussion of some wound care products as they relate to chronic wound care will be presented. 


\section{Types of chronic wounds Pressure ulcers}

Pressure ulcers are, as their name implies, caused primarily by unrelieved pressure. They usually occur over bony prominences such as the sacrum or the heel, but can occur on any part of the body subjected to pressure. The damage causing a pressure ulcer can occur in a matter of hours. Shear forces and friction may also contribute to the formation of pressure ulcers. Pressure ulcers are described as stages relating to the depth of tissue damage incurred. In February 2007, the National Pressure Ulcer Advisory Panel (NPUAP) released updated definitions of these stages in order to clarify misconceptions and reduce confusion that had been a frequent complaint with the original definitions put forth by Shea. ${ }^{4}$

These stages are used to describe pressure ulcers only (Figure 1). Other wound classification systems include partial or full thickness wounds. Partial thickness wounds involve only the epidermis and dermis. Full thickness wounds involve deeper tissues and structures. Diabetic foot ulcers also have unique classification systems to be described later.

\section{Pressure ulcer prevention}

Prevention of pressure ulcers is of paramount importance, and begins with a complete history and physical to determine risk factors. ${ }^{8}$ However, not all pressure ulcers are avoidable. As noted by Langemo and Brown, skin, as other organ systems can also fail. ${ }^{3}$

Even with appropriate treatment, Stage IV ulcers may require surgical intervention such as surgical flaps, deep debridement or possibly amputation. Healing Stage IV ulcers may take years and, as with any wound that heals by scar formation, result in tissue that is only $40 \%-80 \%$ of the tensile strength of undamaged tissue. Development of a pressure ulcer has been implicated in increased mortality, although the causal relationship has not been established. ${ }^{1}$

Potential interventions for prevention of pressure ulcers include the repositioning, nutrition, moisturizing dry skin or by preventing damp skin by targeting fecal or urinary incontinence and the use of special support surfaces. Urinary and fecal incontinence place the skin at risk not only due to excessive moisture, but also because of the chemical properties of urine and feces. ${ }^{9-10}$

Specialized support surfaces redistribute pressure on the skin and subcutaneous tissue. Unrelieved pressure can impair circulation and lead to ulcer formation. Pressure redistributing surfaces can be static or dynamic. Dynamic support surfaces mechanically vary the pressure under the patient thus reducing the length of time a particular skin area is under pressure theoretically improving circulation. Example of dynamic support surfaces include alternating pressure mattresses, low air loss mattress replacement systems, and air fluidized mattresses. A dynamic surface is recommended when the patient cannot reposition themselves, be adequately repositioned without weight bearing on a pressure ulcer or if the patient fully compresses the static surface. ${ }^{8}$ Examples of static support surfaces are foam mattresses or static flotation (air cells, gel, fluid overlays that are placed on top of the mattress). ${ }^{8}$ Foam overlays are no longer used for pressure redistribution. They do not function well and may violate fire codes.

Repositioning or turning patients while in bed is one of the most important ways to prevent pressure ulcers although passive positioning alone has not been shown to decrease the incidence of ulcer formation. ${ }^{1}$ The accepted standard of care is to turn patients at least every two hours. Minimizing pressure in the skin will help maintain circulation to areas that are at risk for breakdown. It is important to keep pressure off areas such as the heels that are at risk for breakdown. This can be accomplished both by turning patients from side to side while in bed and floating the heels above the mattress by placing pillows, etc under the legs.

Nutrition is thought to be important in ulcer prevention although there is not a strong body of supporting evidence. A study by Bourdel-Marchasson and colleagues studied 672 critically ill inpatients older than 65 comparing a standard diet to a standard diet plus two oral nutritional supplements per day. ${ }^{11}$ Patients receiving a standard diet had a relative risk of 1.57 when compared to a group receiving standard diet plus two nutritional supplements. Nutritional evaluation includes serum albumin and pre-albumin levels, although decreased levels may reflect production of inflammatory cytokines not actual nutritional status. ${ }^{1}$

Proper skin moisture is also important in preventing skin ulcers. Dry sacral skin is a known risk factor for developing pressure ulcers. Hence, moisturizing dry skin may help prevent pressure ulcers. Massaging areas at risk over bony prominences while applying moisturizing lotions or cream may increase the risk of breakdown.

Skin that is frequently too wet by contact with urine or perspiration is at greater risk for breakdown. Improvement in continence care with interventions such as toileting patients every two hours, use of skin protectant barrier creams, etc., help maintain skin health. ${ }^{10}$

\section{Vascular ulcers}

Vascular ulcers result from deficits in either quality of arterial flow or derangement of the venous system. The prevalence of 


\begin{tabular}{|c|c|}
\hline $\begin{array}{l}\text { - Ntage I } \\
\text { does not resolve with } 30 \text { minutes of complete } \\
\text { pressure relief } \\
\text { - Darkly pigmented skin lesions may present as } \\
\text { darkening of the damaged tissue or may differ } \\
\text { in texture, temperature or consistency from the } \\
\text { surrounding tissue. } \\
\text { Area at risk is sometimes identified as a } \\
\text { "heralding lesion" it indicates potential for } \\
\text { increased damage if not addressed } \\
\text { immediately. }{ }^{5-6}\end{array}$ & 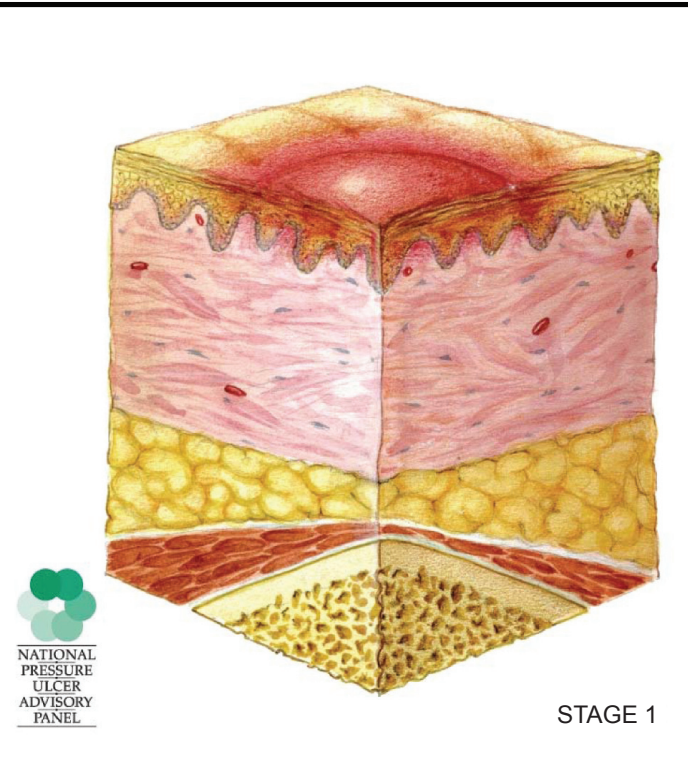 \\
\hline $\begin{array}{l}\text { Deep tissue injury } \\
\text { - New category added to the pressure ulcer } \\
\text { staging system called deep tissue injury (DTI). } \\
\text { of intact skin that may indicate damage to the } \\
\text { underlying tissue. } \\
\text { DTI can heal or progress to a deep ulcer in a } \\
\text { short period of time even with optimal and } \\
\text { aggressive treatment. } \\
\text { Evaluation initially may be confusing if the } \\
\text { hyperpigmented or bruised area is a result of } \\
\text { DTI. One should err on the side of caution and } \\
\text { identify the lesion as a suspected DTI. }{ }^{5-7}\end{array}$ & $\begin{array}{r}\text { SUSPECTED } \\
\text { DEEP TISSUE INJURY }\end{array}$ \\
\hline
\end{tabular}

Stage II
- Ulcers involve the epidermis and dermis only.
(Partial thickness)
- Ulcer presentation may be as a serum-filled
blister or a shallow, superficial ulcer with a pink
or red wound base.
- Lesions may be painful.
Slough, eschar or bruising are not present at
this level.

Figure I Pressure ulcer staging. Images are reused with permission from the National Pressure Advisory Panel. Copyright $\odot ~ 2009$. http://ww.npuap.org/. 


- Ulage III
damage does not expose tendon, bone or joint
capsule.
Anatomical location and the depth or
composition of the underlying tissue determine
whether the ulcer is relatively shallow or deep.
Areas that have no subcutaneous tissue may
be relatively shallow, but areas with a thick
cushion of adipose tissue may be deep but
bone is not exposed or directly palpable.
Undermining or tunneling may be seen with
these lesions. ${ }^{5-6}$
Undermining is tissue destruction extending
under the skin along the perimeter of the
wound with a relatively wide opening.
Tunneling, on the other hand, has a relatively
small opening, but the tissue loss may extend
deeply into the adjacent tissue.

\section{Stage IV}

- Pressure ulcer may extend into muscle, and in some cases, erode bone, tendons, ligaments and other supporting structures.

- Ulcer may have slough or eschar in portions of the wound bed and undermining and/or tunneling is common.

- Anatomical location dictates the depth of the wound, but the hallmark is the exposure of deeper supporting structures. ${ }^{5-6}$

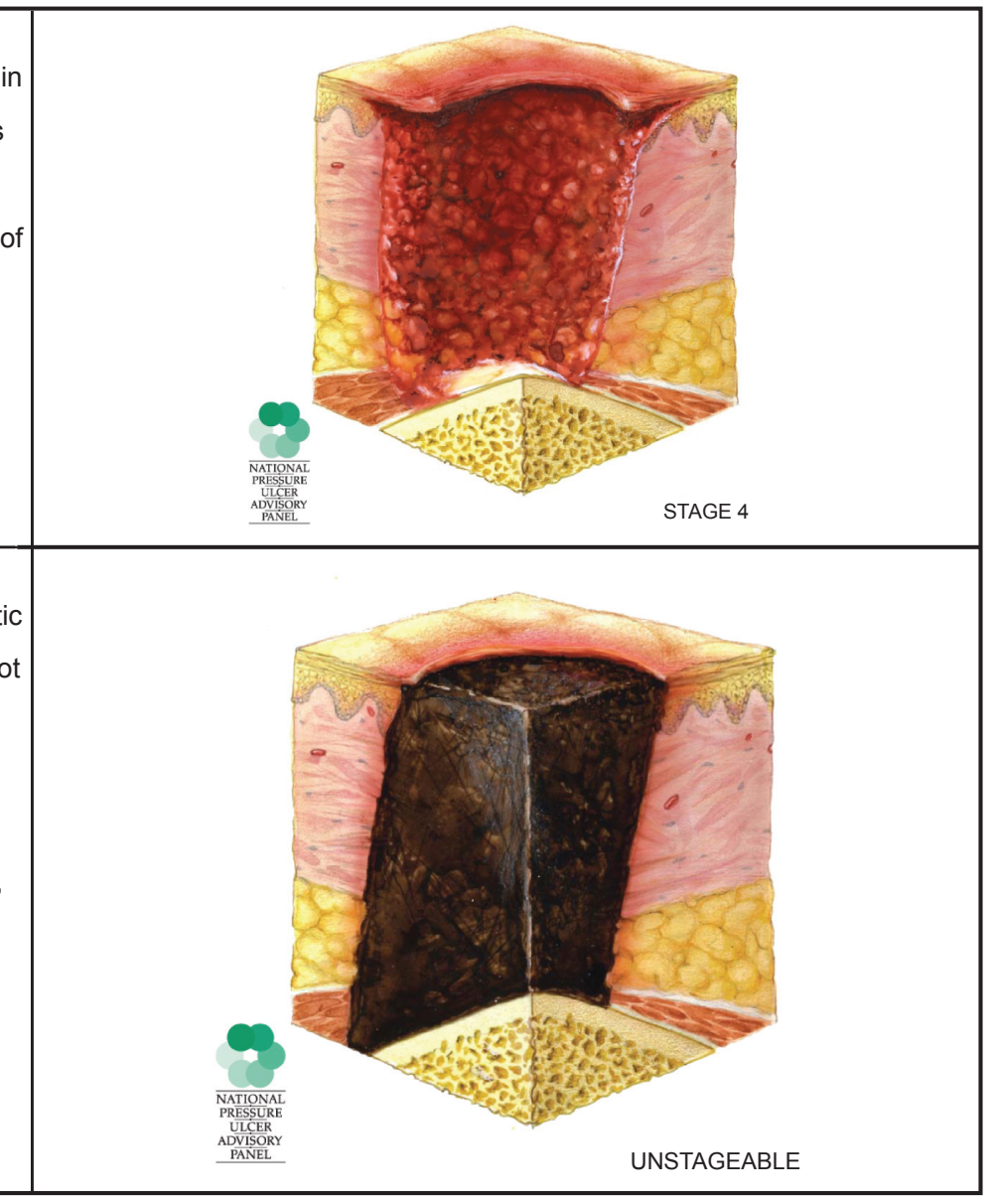

\section{Unstageable}

- Ulcers covered with slough, eschar or necrotic debris to the extent that the wound base is not visualized are classified as unstageable.

- Slough is soft nonviable tissue that may be yellow, gray, tan or green. Eschar is desiccated necrotic tissue and may be black, gray or brown. ${ }^{5-6}$

- Presence of slough or eschar indicates that the ulcer is at least Stage III because these tissues arise from subcutaneous fat or devitalized muscle. 
peripheral arterial and peripheral venous disease is increased in the geriatric population. Evaluation must include both systems because these problems are not mutually exclusive.

\section{Arterial ulcers}

Arterial ulcers are a result of restriction of flow or occlusion of an artery. They have a discrete "punched out" appearance, a pale wound bed and minimal exudate. Gangrene or necrotic tissue is common. Due to the ischemia underlying the development of these ulcers, they are often very painful and difficult to treat or heal. ${ }^{12}$ The most frequent locations for these ulcers are the tips of or between the toes, over the phalangeal heads, or over the lateral malleolus. Even a bump or scrape can precipitate an ulceration. ${ }^{13}$

If an arterial or ischemic ulcer is suspected, then the site should be evaluated for adequate blood flow. For leg and foot ulcers if there is a palpable dorsalis pedis pulse, the ankle systolic pressure is at least $80 \mathrm{~mm} \mathrm{Hg}$ or higher and the brachial systolic pressure at least $100 \mathrm{~mm} \mathrm{Hg}$. These values are usually indicative of enough pressure to heal a wound. If a pulse is nonpalpable then evaluation of blood flow by Doppler ultrasound is important. The Ankle Brachial Index (ABI) is used to determine quality of blood flow and ascertain if a wound is healable. ${ }^{16}$ The ABI is calculated by dividing the dorsalis pedis systolic pressure by the brachial artery systolic pressure. A value less than 0.5 (moderately severe ischemia) means that it will be difficult for the wound to heal. ${ }^{16}$ If the ABI is greater than 1.2 (especially in the diabetic or renal failure patient) it may mean that the vessels are heavily calcified, which can produce a falsely elevated ABI. Toe pressures can then be used because the vessels supplying the toes do not have calcium deposits. Toe pressures greater than $50 \mathrm{~mm} \mathrm{Hg}$ are normal; whereas values of less than 30 are grossly abnormal. Frequently, wounds can heal with toe pressure values between $30-50 \mathrm{~mm} \mathrm{Hg} .{ }^{17}$

The treatment of arterial ulcers is based on optimization or restoration of adequate perfusion and may be achieved by risk factor modification, activity and positioning, medication or surgical treatment. ${ }^{13}$ Risk factor modification includes smoking cessation, controlling diabetes, hypertension, and hyperlipidemia. A daily walking program is encouraged. Leg elevation is relatively contraindicated in patients with arterial ulcers. Patients with arterial ulcers should wear compression bandages or stockings only with careful consideration of the risks and benefits and with close monitoring.

Two drugs are approved by the Federal Drug Administration (FDA) for promoting blood flow in patients with arterial ulcers or claudication: pentoxyphilline (Trental), and cilostazol (Pletal). These medications are phosphodiesterase inhibitors that prevent platelet aggregation. Trental improves erythrocyte and leukocyte flexibility and thins the blood. Pletal also increases vasodilatation. However, its use is contraindicated in patients with congestive heart failure. ${ }^{14}$

Surgical treatment is recommended for patients with rest claudication who are at risk for limb loss. ${ }^{13}$ The site of arterial occlusion can partially be determined by the location of pain or fatigue. Occlusion of the aorta or iliac arteries causes symptoms in the buttocks or hips, femoropopliteal disease causes symptoms in the calf. ${ }^{15}$ Bypass grafting, stent placement, or angioplasty are possible options for intervention.

\section{Venous ulcers}

Venous ulcers are caused by venous hypertension resulting in uncontrolled edema. Venous hypertension may result from a deep vein thrombosis (DVT) or postphlebitic syndrome, obesity, congestive heart failure or severe trauma to the leg. The visible changes in the tissue of the leg associated with venous hypertension are: hemosiderin staining, the hyperpigmentation resulting from red blood cells leaking into the tissue and deposition of the heme; stasis dermatitis marked by erythema, edema, scaling, and weeping of serous fluid; lichenification, thickening of the tissue; and skin ulceration. ${ }^{12,18}$ Long-term untreated or under-treated venous hypertension, may result in development of lymphedema, which further complicates treatment.

Venous ulcers are generally shallow with irregular wound margins. The ulcer base tends to be beefy red and granulation is frequent with exudates most often moderate to heavy. If there is an arterial component, the color and amount of exudates may be muted. These wounds may have a strong odor that may be concerning to the patient and must be addressed when providing wound care. Venous ulcers are classically located over the medial malleolus although sometimes they can be near the lateral malleolus. In severe cases they may encircle the entire ankle. ${ }^{19}$ Other disease processes such as vasculitis, pyoderma gangrenosum, or neoplasms may be mistaken for venous ulcers. Ulcers that do not respond to standard treatment should be referred for further evaluation, ie, dermatology, vascular or plastic surgery, etc.

The treatment of venous ulcers includes specific recommendations regarding activity, positioning and compression therapy. Standing or sitting with the legs in a dependent position should be discouraged. Patients should shift their weight frequently when standing and should be encouraged to have a daily walking program. Leg elevation above the level of the heart is recommended to reduce edema. Compression therapy is essential to venous ulcer healing and prevention of recurrence. Before compression therapy can be used arterial 
status should be evaluated and deemed to be adequate. ABIs of 0.5 or greater are required to initiate compression therapy. Many types of compression devices are available that provide sustained graduated compression at a therapeutic level. These include elasticized tubular support bandages, elastic wraps, custom fitted compression stockings and wraps with hook and loop closure such as CircAids. ${ }^{20}$ The Unna boot is an example of rigid compression therapy that goes on wet but dries to becomes rigid, it works through enhancement of the calf muscle pump and is appropriate for ambulatory patients. ${ }^{20}$ There are several multi-layer elastic compression systems available that provide moist wound healing, wound protection, absorption of drainage and continuous therapeutic levels of compression. ${ }^{18}$ Careful consideration of requirements for use of these devices as outlined in the manufacturers guidelines is warranted.

\section{Neuropathic ulcers}

Neuropathy is most often associated with diabetes, but may result from other diseases. Neuropathy falls into three categories: sensory, motor, and autonomic. The most common is sensory neuropathy resulting in an insensate foot. Ulcer causality is multifactorial, the presence of sensory neuropathy, peripheral occlusive vascular disease and the presence of bony deformities increase the incidence of foot ulcers. ${ }^{21}$ Diabetic foot ulcers may be classified in stages according to the natural history progression: 1) normal foot; 2) high risk foot; 3) ulcerated foot; 4) infected foot; 5) necrotic foot. ${ }^{22}$ Patients with loss of protective sensation have been shown to have a 15 fold increase in the risk of developing a foot ulcer. ${ }^{23}$ When the protective sensory threshold is lost, patients may continue to experience tissue damaging pressure or trauma. The ulcers are typically located in areas exposed to repetitive pressure and the precursor of callus or blister formation can alert patients and providers alike to an impending ulcer. Callus formation is a normal response to the stress of elevated pressures on an area of the foot. The callus can act like a stone (local pressure) in the shoe. ${ }^{24}$ Repetitive pressure can lead to formation of an ulcer at the site of the callus. Ulcers can occur undetected under a callus and only declare themselves with an infection that threatens the foot or lower limb. Testing for protective sensory threshold is done with a Semmes-Weinstein 5.07/10 gm monofilament (Semmes-Weinstein Corp., NY, USA). ${ }^{24}$

Motor neuropathy causes an imbalance in the forces of flexor versus extensor muscles, with the stronger flexor muscles generally overpowering the extensors causing deformities such as hammer toes, claw toes, etc. These deformities change the configuration of the protective pads of the foot leaving the joints in jeopardy for breakdown. As the toes contract the patient walks on the tips of the toes instead of the plantar surface, the phalangeal heads become more prominent and subject to pressures from the shoes. The protective pads over the metatarsal heads are also pulled forward leaving the tissue over them at high risk for development of pressure ulcers.

Autonomic neuropathy causes a decrease in sweating leading to excessively dry skin. This can cause the skin to dry and thicken, often resulting in painful fissures that are a potential portal for infection. ${ }^{25}$ Loss of autonomic regulation allows dilatation of the blood vessels of the foot, demineralization, and softening of the bones leading to Charcot foot deformities. $^{25}$

Prevention of diabetic neuropathic foot ulcers is paramount; $60 \%$ of nontraumatic lower-limb amputations are diabetes-related. ${ }^{26}$ People with diabetes should wear comfortable well fitting shoes and never walk barefoot. Glucose control needs to be optimized to help prevent neuropathy and aid in healing. Calluses or corns should be treated by a professional. Patients providing self-care must follow their professional's guidelines and instructions carefully. Off-loading pressure on the ulcer is necessary using devices such as wheelchairs, crutches, walkers, total contact casts, total contact sandals, short leg walkers and wedged healing shoes. ${ }^{19}$ If adequate blood flow is present, periwound hyperkeratosis needs to be debrided with the wound margin being "saucerized" (debrided so wound margins slope like a shallow bowl, thereby reducing pressure and optimizing wound healing). Surgical correction of a specific foot deformity may be required. ${ }^{23}$

Other modalities are being used for treatment of nonhealing diabetic foot ulcers including negative pressure wound therapy, recombinant human growth factors and skin substitutes. The US FDA has issued an ongoing safety review regarding becaplermin (Regranex), a topical recombinant form of human platelet-derived growth factor: “... there may be some evidence for an increased risk of death from cancer in patients who had repeated treatment with Regranex." 27 The risk of a nonhealing diabetic foot ulcer should be weighed against the possible risk of using Regranex on an individual basis. $^{27}$

\section{Stages of healing}

There are four major stages of healing of acute wounds. They include coagulation, inflammation, proliferation and maturation. During coagulation platelets start healing by releasing mediators such as growth factors. In inflammation, 
there is vasodilatation, an increase in capillary permeability, complement activation and migration of neutrophils and macrophages to the site. The neutrophils and macrophages destroy bacteria, release proteases, and secrete growth factors. Inflammation is regulated by bacteria and cytokines.

Cell proliferation occurs when fibroblasts, endothelial cells, and keratinocytes promote cell migration, proliferation, angiogenesis and synthesis of extracellular matrix components. Remodeling or maturation occurs over several weeks to months after a new scar is formed and collagen fibers are rearranged into a more orderly configuration modifying the appearance of the scar tissue. ${ }^{28}$

Unfortunately chronic wounds become stalled in the inflammation stage and do not progress to the proliferation stage. Chronic wounds have an increase in proinflammatory cytokines. They also have an increase in matrix metalloproteinases (MMPs). MMPs are a family of zinc-dependent endopeptidases secreted as inactive zymogens. They are capable of degrading most extracellular components and basement membrane proteins at a neutral $\mathrm{Ph}$. Within the skin they are produced by keratinocytes, fibroblasts, neutrophils, macrophages, mast cells and eosinophils. This proinflammatory environment contains many proteins that break down the developing collagen matrix and impede healing. ${ }^{29}$ Products such as Promogran (Johnson and Johnson Wound Management, Somerville, NJ, USA), BioStep or BioStep Ag (Smith and Nephew, London, UK) are collagen matrix dressings that also contain other components. Placed in the wound base it may prevent the breakdown of growth factors and reduce the effect of MMPs. ${ }^{30}$

\section{Major considerations in treating a chronic wound}

Bacterial balance, necrotic tissue, and moisture balance comprise the three major considerations in treating a chronic wound. These areas must be addressed in order for healing to occur.

\section{Bacterial balance}

All wounds contain some bacteria. The question is whether the amount of bacteria merely represents colonization of the wound or represents bacterial overgrowth and infection. The latter can lead to impaired wound healing. ${ }^{28}$

There are many signs and symptoms which suggest bacterial over growth and infection. Either a subclinical or overt infection may prevent wound healing. Signs and symptoms include change in wound exudate that may be clear or serous then become purulent in appearance, an unpleasant odor from the wound can indicate superficial or deep infection. Bacterial stimulation of vascular endothelial growth factor (VEGF) can occur which stimulates new blood vessel formation and hence makes the area more likely to bleed. An increase in cutaneous temperature and increased surrounding erythema suggests an infection. ${ }^{28,31}$

Treatment of bacterial overgrowth and infection is determined by whether the infection is superficial or deep. Superficial bacterial overgrowth can be treated with topical agents. Deep tissue infections such as cellulitis, muscle, and bone (osteomyelitis) infections must be treated with systemic antibiotics and frequent debridement. ${ }^{16}$ Oral antibiotics may be used for less severe infections with intravenous (IV) antibiotics reserved for more severe infections such as advancing cellulitis or osteomyelitis. Antibiotics are determined by Gram stain and suspicion initially and adjusted based on bacterial identification with antibiotic sensitivity. The microbial flora of a chronic wound changes over time. In an early wound, Gram-positives such as Staphylococcus aureus and beta-hemolytic streptococci predominate. After four weeks, Gram-negative rods ie, Proteus, Escherichia coli and Klebsiella will colonize the wound. Later on anaerobes come into play and after several months the average wound may be colonized by 4-5 different organisms. ${ }^{28}$

Superficial bacterial overgrowth can usually be treated with topical agents, sometimes as simple as normal saline, which can keep a chronic wound clean. Wounds that have no chance of healing should also be treated with topical agents with the goal of preventing the nonhealing wound from becoming infected.

Examples of topical agents are chlorhexidine, betadine, acetic acid, hydrogen peroxide, scarlet red dye, and bacitracin. Chlorhexidine and betadine are broad spectrum and have low tissue toxicity. Acetic acid is effective against pseudomonas. Dyes are effective against Gram-positive cocci but not against Gram-negative bacteria. ${ }^{28}$ These agents should be used for cleansing dirty or infected wounds only and not for clean wounds as they may cause damage to the wound bed. ${ }^{16}$

Broad-spectrum antimicrobials such as silver products, polyhexamethylene biguanide, Cadoxemer Iodine or polyacrylates are beneficial in decreasing the bioburden of a chronic wound and are also used to treat superficial infections. ${ }^{16}$ Silver-based agents are also used to treat superficial infection. There are a wide range of silver-based agents. Examples of such agents include: hydrogels, alginates, foams, negative pressure wound therapy foam dressings, and some compression garments. The controversy in the industry is whether the 
total amount of silver or the chemically available amount is more important in bacterial control. Silver dressings should be chosen according to the amount of silver released and their relative moisture absorption and retentive properties. ${ }^{33}$

\section{Dealing with necrotic tissue through debridement}

Necrotic tissue impedes the healing of both acute and chronic wounds. It impairs the development of granulation tissue and impairs the migration of keratinocytes that are required for re-epithelialization. ${ }^{16,34}$ Necrotic tissue can also serve as a medium for bacterial overgrowth. Removing the necrotic tissue reduces the bacterial burden. ${ }^{16,17}$

Evaluation of a wound's potential for healing is a prime consideration in treatment choices. Determining whether a wound can heal is accomplished by evaluating whether the wound has an adequate blood supply. Checking for pulses, capillary refill and Doppler pressures are ways to determine if a blood supply is adequate. ${ }^{16-17}$

Debridement of an ischemic wound increases tissue loss and the risk of infection and is therefore contraindicated. An example of this is dry gangrene of the toes. Debriding or increasing moisture in ischemic lesions may convert dry gangrene to wet gangrene and hasten a life threatening infection. If a wound has an adequate blood supply, then debridement of necrotic tissue should be considered. Several methods of debridement are available. Sharp or surgical debridement is removal of necrotic tissue with scissors or a scalpel blade and forceps. This can be performed in a clinic setting or at the bedside. If indicated, premedication of the patient with topical, oral or parenteral pain medication reduces patient discomfort and facilitates adequate debridement. Sharp surgical debridement is the most rapid way to remove necrotic tissue and has been shown to be effective in treating diabetics with neuropathic foot ulcers. It has also been shown to be effective in treating difficult to heal venous ulcers when compared to no debridement. ${ }^{17}$

Autolytic debridement occurs when the wound is covered with a dressing and the body's own proteolytic enzymes released by macrophages act to liquefy necrotic tissue. Hydrogels, films and hydrocolloids are some of the dressing types that facilitate autolytic debridement (Table 1). Use of these dressing must be carefully considered in the presence of an incompetent immune system. Wounds must be carefully cleansed prior to application of a new dressing. ${ }^{17}$

The third method of debridement is with an enzymatic agent (EA). Collagenase remains the only EA still available in the United States. Dressings with EAs must be changed at least once a day. Wounds should be closely monitored, as the EA can sometimes damage healthy tissue at the margins of the dressing. ${ }^{17}$

Mechanical debridement is achieved by use of the classic wet-to-dry dressing and whirlpool or hydrotherapy. Wet-to-dry dressings involve packing a wound with salinemoistened gauze and covered with a dry dressing. The dressing is allowed to dry and is then quickly removed along with adherent tissue. Unfortunately, it is nonselective and can remove vital tissue as well as necrotic tissue, may be very painful and may prolong healing time. This dressing technique is never indicated for use in clean, granulated wounds. Whirlpool therapy uses the action of fast-moving water to remove necrotic tissue. This strategy is rarely used, as it has not been shown to be very effective and may increase lower extremity edema. ${ }^{17}$

Maggot therapy can also be used to debride some wounds. Sterilized greenbottle fly maggots are applied to the wound every 2-3 days. Maggots secrete enzymes into the wounds which act like proteases to degrade necrotic tissue. The larvae have the ability to digest bacteria and can help with heavily colonized wounds. Maggot therapy has been shown to decrease wound size. ${ }^{16,17,34}$

\section{Moisture balance}

In addition to bacterial burden and debridement of necrotic tissue, moisture balance must be considered when looking at the bed of a chronic wound. In the remote past it was considered best to have a dry wound to facilitate healing but more recent research has proven that healing is accelerated in a moist wound environment. A wound with too much moisture and drainage can damage surrounding tissue causing maceration. ${ }^{36}$

The components in the exudate of chronic wounds differ significantly from those of acute wounds. Acute wounds are rich in growth factors that help promote the generation of fibroblasts, epithelial cells and keratinocytes. In contrast, exudate in the chronic wound has higher concentrations of MMPs, proenzymes that tend to degrade the wound matrix that is optimal for wound healing. Hence for chronic wounds it is necessary to remove excessive exudate or moisture high in MMPs. ${ }^{36}$

The wound environment must maintain proper moisture balance. This can be done by increasing moisture to wounds that are too dry and decreasing the moisture of wounds that are too wet. Some of the newer generation of wound dressings are designed to do this. Research continues to work toward the development of the "ideal dressing" that can 
Table I Examples of dressing types

\begin{tabular}{|c|c|c|}
\hline & Trade name & Manufacturer \\
\hline \multicolumn{3}{|l|}{ Films } \\
\hline & Tegaderm & $3 M$ \\
\hline & OpSite & Smith and Nephew \\
\hline \multirow[t]{3}{*}{ Bioclusive } & & Johnson and Johnson \\
\hline & Transparent film dressing & Invacare \\
\hline & Polyskin II Transparent & Kendall \\
\hline \multicolumn{3}{|c|}{ Hydrocolloids } \\
\hline & Tegaderm Hydrocolloid Dressing & $3 M$ \\
\hline & Cutinova & Smith and Nephew \\
\hline & Replicare Hydrocolloid Dressing & Smith and Nephew \\
\hline & CombiDERM ACD Cover Dressing & ConvaTec \\
\hline & Duoderm CGF Control Gel Dressing & ConvaTec \\
\hline & Comfeel Plus Clear Dressing & Coloplast \\
\hline & Restore Extra Thin & Hollister \\
\hline & Restore Hydrocolloid Dressing & Hollister \\
\hline \multicolumn{3}{|l|}{ Hydrogel } \\
\hline & CURAGEL & Kendall \\
\hline & Curasol Gel Wound Dressing & Healthpoint \\
\hline & DuoDERM Hydroactive Gel & ConvaTec \\
\hline & Normigel $0.9 \%$ Isotonic Saline Gel & Molnlyke \\
\hline & NU-GEL Wound Dressing & Johnson and Johnson \\
\hline & Restore Hydrogel Dressing & Hollister \\
\hline & Tegaderm Hydrogel Dressing & $3 M$ \\
\hline \multicolumn{3}{|l|}{ Alginate } \\
\hline & AlgiSite M Calcium Alginate Dressing & Smith and Nephew \\
\hline & CURASORB & Kendall \\
\hline & Calcium Alginate Wound Dressing & Invacare \\
\hline & KALTOSTAT & ConvaTec \\
\hline & NUDERM Dressing & Johnson and Johnson \\
\hline & Restore Calcium Alginate Dressing & Hollister \\
\hline & Restore Silver Calcium Alginate Dressing & Hollister \\
\hline & Sorbsan Wound Dressing & UDL Laboratories \\
\hline \multicolumn{3}{|l|}{ Foam } \\
\hline & Tegaderm Foam Adhesive & $3 M$ \\
\hline & Allevyn & Smith and Nephew \\
\hline & Biatain Adhesive Foam Dressing & Coloplast \\
\hline & COPA Hydrophilic Foam Dressing & Kendall \\
\hline & Invacare Polyurethane Foam Dressing & Invacare \\
\hline & Lyofoam & ConvaTec \\
\hline & Mepilex & Molnlyke \\
\hline
\end{tabular}

address the major concerns in wound care. In 1979, Turner described the ideal dressing as possessing the following characteristics:

- Removes excess exudates and toxins

- Provides high humidity at the dressing wound interface

- Allows for gaseous exchange
- Provides thermal insulation

- Protects against secondary infection

- Remains free from particulate and toxic components

- Causes no trauma on removal. ${ }^{37}$

These characteristics are still pertinent today. Some of the many types of wound dressings will be discussed below. 


\section{Treatments or dressings that increase moisture Transparent films}

Film dressings exist in either adhesive or non-adhesive forms. They are made of either polyurethane or synthetic polymer sheets. They are frequently used to cover IV catheter sites and are sometimes used to help protect or heal partial thickness wounds. They have no ability to absorb excess moisture and cannot be used as a primary dressing for exudating wounds. They are best used for treating superficial, nonexudative wounds or during the late stages of wound healing. ${ }^{38}$ Combined with cross-hatching of eschar (cutting through the thick, dry tissue in a grid pattern) with a scalpel, covering the wound with a transparent film can quicken debridement. ${ }^{28}$

\section{Hydrocolloids}

Hydrocolloids have an inner hydrocolloid gelling agent that is made of carboxymethylcellulose (CMC) combined with pectin. This is sandwiched between an inner adhesive layer that rests on the wound surface and an outer coating of foam or a film. ${ }^{36}$ The hydrocolloid gel absorbs moisture when exposed to the wound exudate and forms a gel. As hydrocolloids absorb more moisture, they become more water permeable. This allows them to transmit moisture and manage wound exudate. Due to their hydrating properties with the mixture of the patient's own endogenous enzymes, hydrogel dressings are useful in autolytic debridement of the wound bed. ${ }^{36}$ When the dressings are removed they may leave some of the gelling agent behind which can have a foul odor and be confused with infection, therefore it is imperative to cleanse and assess the wound after removal of the dressing. These should be changed every $2-7$ days as needed, indicated either by leaking of exudate, loosening or displacement of the dressing.

Hydrocolloids are useful in treating venous ulcers, pressure ulcers and (if used judiciously) diabetic foot ulcers. ${ }^{36}$ They are relatively contraindicated with treating arterial insufficiency, vasculitis, and infection. ${ }^{34}$

\section{Hydrogel dressings}

Hydrogel sheet dressings are semi-occlusive and composed of a cross linked network of hydrophilic polymers. ${ }^{36}$ Semiocclusive dressings enhance autolytic debridement of dry to mildly exudative wounds. They are useful in burn patients because they have a soothing effect, but should not be used in ischemic ulcers. All hydrogel sheets are somewhat transparent and allow monitoring of the wound without removing the dressing. They should be changed every 24 to 72 hours. Wound treatment gels are either isotonic or hypertonic depending on whether the intent is to maintain a moist wound environment or to enhance debridement and are used with a secondary dressing.

\section{Treatment or dressings that reduce moisture Calcium alginate dressings}

Alginate dressings are made from kelp and consist of calcium alginate polysaccharides. They work through a sodium-calcium ion exchange between the wound exudate and the dressing. This produces a sodium-alginate gel with moisture retaining or absorbing properties making them useful for treating draining or infected wounds. The calcium ions released by these dressings also aid in the coagulation pathway. This type of dressing may be useful in bloody exudative wounds. Alginates high in mannuronic acid form a soft gel that partially dissolves in solutions containing sodium ions, such as wound exudate. Alginates with high concentrations of guluronic acid, retain their integrity and structure throughout the gelling process. ${ }^{39}$ When removed from the wound, these dressings frequently have an odor and may give the appearance of an infected wound. It is important to cleanse the wound before assessing for the presence of infection. Alginates are useful in wounds with moderate to heavy exudates. The concomitant use of topical antibiotics or other antimicrobial agents may decrease absorption of fluids. ${ }^{41}$

\section{Foam}

Foam dressings have an absorbent porous hydrocellular polyurethane center which is laminated with a semi-occlusive outer layer. ${ }^{28}$ Foam dressings are configured with different outer layers that have varying moisture vapor transmission rates. Dressings that have higher moisture vapor transmission rate allow moisture to be transmitted through the dressing and evaporated. This property makes these dressings useful in highly exudative wounds. ${ }^{28}$

Foam dressings may be either adherent or nonadherent and come in a variety of shapes and absorbency. They have different degrees of flexibility and density and many can be shaped to fit wounds of any size and depth. The opacity of the dressing prevents inspection of the wound without removal. 


\section{Hydrofiber}

Hydrofiber dressings are available in sheets or ropes. They are composed of highly absorbent sodium CMC. They are indicated for wounds that have moderate to heavy exudate. Because they are nonadherent, they require a secondary dressing to keep them in place. Hydrofiber dressings are useful in the treatment of draining chronic venous ulcers. Both foam and hydrofiber dressings have wear times of up to one week. ${ }^{28}$

\section{Composite dressings}

Composite dressings are comprised of multiple layers with varying absorbent properties. They are useful in exudate control and as a secondary dressing for foams, alginates, and hydrofibers. They can be used under a compression dressing alone or in combination with other dressings have a wear time of up to one week. ${ }^{29}$

\section{Synthetic skin grafts}

Synthetic skin grafts, also called skin substitutes, were developed to avoid the morbidity associated with full thickness skin grafts and to decrease time required for wound healing. ${ }^{30,31}$ Several products (Alloderm, Integra Neurosciences, Plainsboro, NJ, USA; Integra, Integra Life Sciences, Plainsboro, NJ, USA; Apligraf, Novartis, Basel, Switzerland; Dermagraft, Advanced BioHealing, LaJolla, CA, USA) are on the market and are bioengineered from cells derived from different sources. ${ }^{31}$ Synthetic skin grafts have been shown to increase the likelihood of healing of venous ulcers when compared to conventional dressings. ${ }^{31}$

\section{Negative pressure wound therapy}

Negative pressure wound therapy (NPWT) consists of applying a foam or gauze dressing over the surface of the wound. It is secured with a transparent film to form an airtight seal. Continuous or intermittent negative pressure is applied. Wound healing is accelerated by removing excess interstitial fluid, improving blood flow reducing bacterial count, stimulating angiogenesis and increasing tissue perfusion. ${ }^{31,42}$

\section{Conclusion}

The aging population presents many challenges to the medical community in the provision of care; among them is wounds care. Although it is a complex subject, basic understanding of the healing process, the most common types of ulcers and some of the dressing options available is necessary in caring for these patients. A multidisciplinary approach maximizes wound care in the elderly by drawing on each team member's expertise. The majority of elderly patients with ulcers heal if treated assertively and appropriately. Healing is not possible in many instances. A holistic approach to wound care is paramount. Symptom management, whether healing or palliation is the goal, will improve overall outcomes for the elderly patient. The reward of providing wound care is in assisting a person to an enhanced health-related quality of life.

\section{Case studies}

To illustrate the decision-making process that is involved in care related to specific types of wounds, consider the following case studies:

\section{Case study DM: Venous stasis ulcers}

Mr. DM was a morbidly obese, 66-year-old man when admitted to the hospital with left lower extremity cellulitis and venous ulcers. Pertinent diagnoses: Type II diabetes mellitus, vitamin D deficiency, sleep apnea, history of congestive heart failure, hypertension and hyperlipidemia. Of note, his glycosylated hemoglobin ( $\mathrm{HbAlc}$ ) was 6.9 , albumin was 3.0 (normal 3.5-5.2) and his white blood cell (WBC) count 11,600 . Weight was 274.2 pounds $(124.4 \mathrm{Kg})$, height 73 inches $(160.6 \mathrm{~cm})$, with a body mass index (BMI) of 36.25 .

He was given furosemide $40 \mathrm{mg}$ IV on day one, $40 \mathrm{mg}$ IV bid day two, and another $40 \mathrm{mg}$ IV on day three. He was also started on sulfamethoxazole 800/trimethoprim 180 DS bid. Profore 4-layer compression dressings were applied to bilateral lower extremities for 4+ interstitial edema. Followup care in the wound clinic after discharge from the hospital involved debridement of crusting lesions and Unna boot wrap with compression. Within two weeks, the cellulitis had resolved and the edema was reduced.

Compression stockings (knee high 20-30 mm Hg) were obtained and donned. The following week, his cellulitis had exacerbated. Keflex and clindamycin were given with complete resolution of the infection. He experienced continued edema with use of compression stockings so compression wraps were again initiated and he was measured for CircAids. When the CircAids were received, he was converted to these devices and did well. Edema was controlled and he has had no recurrence of ulcers (Figures 2 and 3).

\section{Case study AL: Pressure ulcers}

Mr. AL was a 67-year-old man admitted to the Nursing Home Care Unit because of adult failure to thrive, malnutrition, depression, and multiple pressure ulcers. He was s/p CVA with left hemi paresis and contractures of both upper and lower extremities. His weight was 105 pounds $(47.6 \mathrm{Kg})$, 


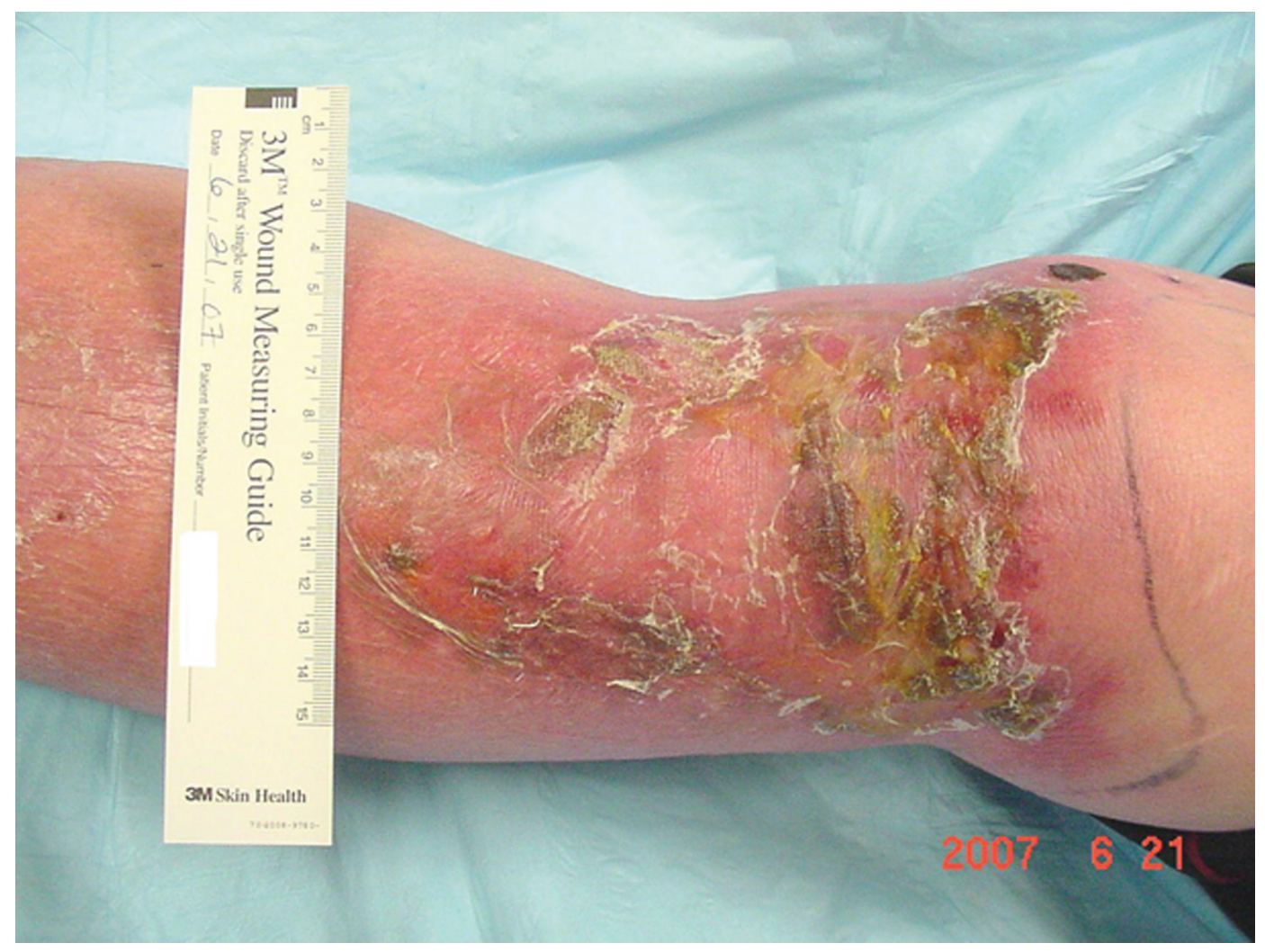

Figure $\mathbf{2}$ Anterior left lower leg, venous hypertension ulcer.

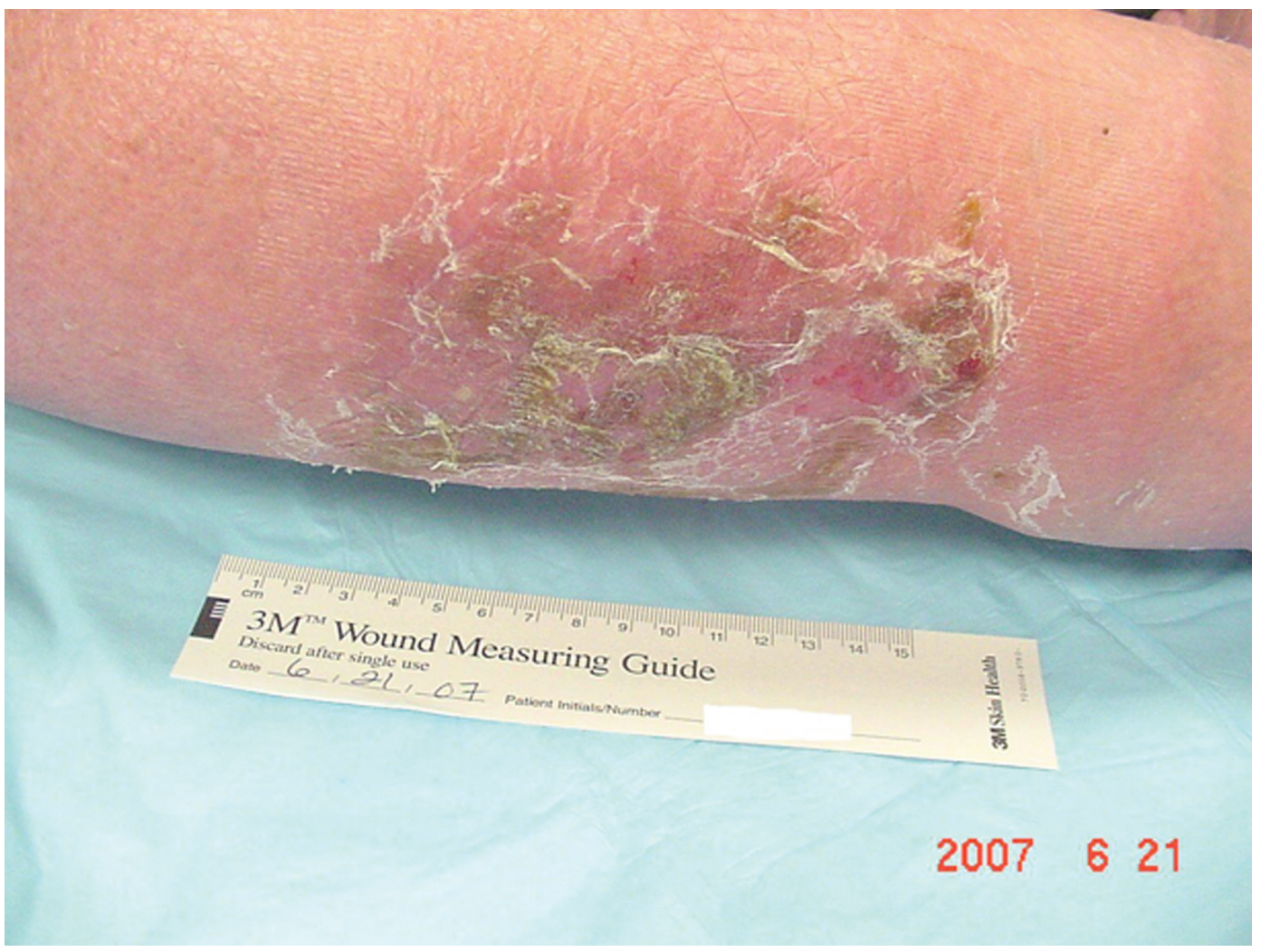

Figure 3 Posterior left lower leg, venous hypertension ulcer. 
Table 2 Mr. AL's pressure ulcer

\begin{tabular}{lll} 
- Left foot medial malleolus & $2.4 \mathrm{~cm} \times 2.2 \mathrm{~cm}$ & Stage IV \\
- Left medial midfoot & $2.0 \mathrm{~cm} \times 0.8 \mathrm{~cm}$ & Stage II \\
- Left medial Ist met head & $0.5 \mathrm{~cm} \times 0.8 \mathrm{~cm}$ & Stage II \\
- Left medial hallux & $1.4 \mathrm{~cm} \times 1.5 \mathrm{~cm}$ & Stage III \\
- Right hip & $7.0 \mathrm{~cm} \times 4.5 \mathrm{~cm}$ & Epithelialized \\
- Posterior right thigh & $0.8 \mathrm{~cm} \times 2.1 \mathrm{~cm}$ & Stage III \\
- Coccyx & $4.2 \mathrm{~cm} \times 3.7 \mathrm{~cm} \times 0.8 \mathrm{~cm}$ & Stage IV \\
- Left hip & $3.0 \mathrm{~cm} \times 3.5 \mathrm{~cm} \times 1.2 \mathrm{~cm}$ & Stage IV \\
- Left hip, eschar & $3.0 \mathrm{~cm} \times 4.0 \mathrm{~cm}$ & Unstageable \\
- Left lateral ankle & $3.8 \mathrm{~cm} \times 3.8 \mathrm{~cm}$ & Stage IV \\
- Left back & $0.7 \mathrm{~cm} \times 1.0 \mathrm{~cm}$ & Stage II \\
- Left wrist & & Healed ulcer \\
\hline
\end{tabular}

height 69 inches $(151.8 \mathrm{~cm})$, and BMI 15.54. On admission he had the following pressure ulcers (Figures 4-9; Table 2):

Initially, all lesions were cleansed with normal saline. Silver alginate was applied to wound bases of Stage III and IV ulcers, covered with composite absorbent dressings (ABDs) and secured with hypoallergenic tape. The silver alginate was intended to decrease bacterial load and absorb exudate and the composite dressings for exudate control. Nonadhering and composite dressings were applied to left foot and secured with roller gauze. The nonadhering dressing was to prevent the dressing from sticking to the wounds and the composite dressings for exudate control. A hydrocolloid dressing was applied to the right thigh ulcer to provide moist wound healing and a bacterial barrier. Pressure-relieving boots were ordered to enhance healing and prevent further damage to feet.

An aggressive plan consisting of a turning and positioning schedule, wound care nutritional support, physical therapy for positioning assistance and occupational therapy for contracture mobilization was instituted. He was placed on a low air loss mattress for pressure redistribution. He had a Foley catheter to gravity drainage for urinary retention due to neurogenic bladder. Care was complicated by fecal incontinence.

Changes were made in the dressing procedures: Collagenase (Santyl) was applied daily to debride left hip ulcers and a composite dressing cover that was secured with hypoallergenic tape. A hydrocolloid dressing over silver alginate was applied to the left hip and coccyx lesions to prevent fecal contamination of wounds, control exudate and provide for moist wound healing. Double layer foam dressings were applied to the bilateral left ankle lesions which consisted of an intact dressing to cover the ulcer for exudate control and to protect the periwound skin, and second layer with hole in center to aid in pressure redistribution. These dressings were secured with roller gauze.

Mr. AL developed contact dermatitis from the foam dressings. Triamcinolone $0.1 \%$ and hydrophilic ointment were ordered and applied every day. The ulcers were healed, no dressings required, use of pressure reducing boots for left foot was continued. His rash resolved.

\section{Case study WC: Diabetic foot ulcers}

$\mathrm{Mr}$ WC was a 64-year old man status post cerebral vascular accidents $\times 5$ with residual right hemiparesis and myocardial infarction $\times 2$. Other pertinent diagnoses include: Type II diabetes.

He developed bilateral posterior heel pressure ulcers and was initially seen in the Podiatry clinic where debridement was performed. Care was coordinated between the Wound Care Clinic, Podiatry and a Home Health Agency Registered Nurse.

The left heel ulcer (Stage III) was 50\% yellow slough and $50 \%$ granulation tissue. The lesion was cleansed with normal saline, a silver hydrogel was applied and a foam dressing with a moisture barrier as a secondary dressing and secured with roller gauze. The right heel ulcer was larger and probed to bone (Stage IV). The wound base was 50\% yellow slough and $50 \%$ granulation tissue. There was a border of hyperkeratotic tissue along the plantar surface. The lesion was cleansed with a solution of $5 \mathrm{cc}$ betadine solution in $500 \mathrm{cc}$ saline and rinsed with normal saline (NS). Kovia ointment (an enzymatic debriding agent) was applied to slough, covered with a saline-moistened gauze and then a dry sterile dressing. Heel protective boots were obtained and donned bilaterally. The patient was provided with supplies for continued treatment by his home health nurse. 


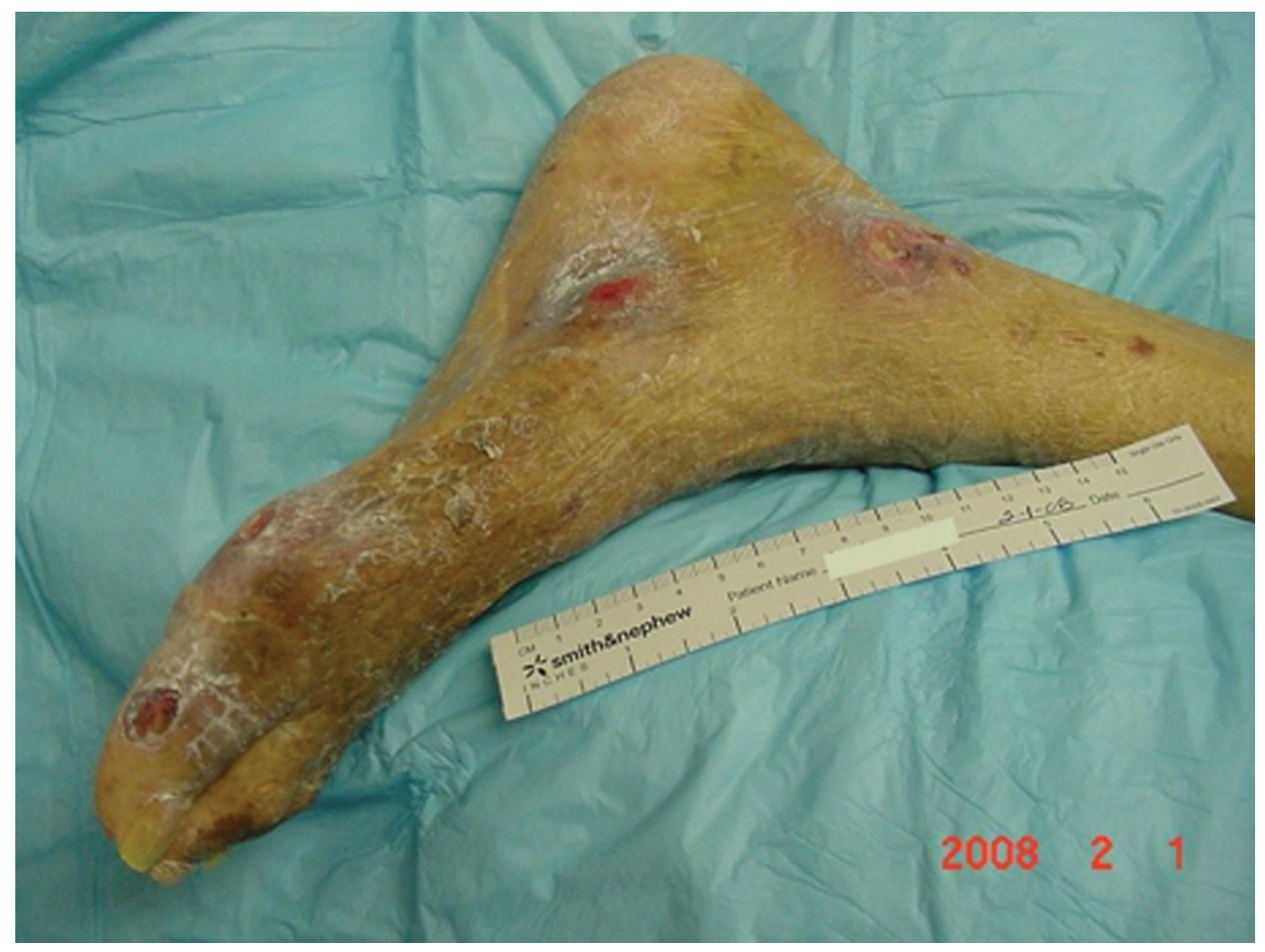

Figure 4 Left foot, medical hallux, Stage III; Medial first metatarsal head, Stage II; Medial mid-foot, Stage II; Medial malleolus, Stage IV.

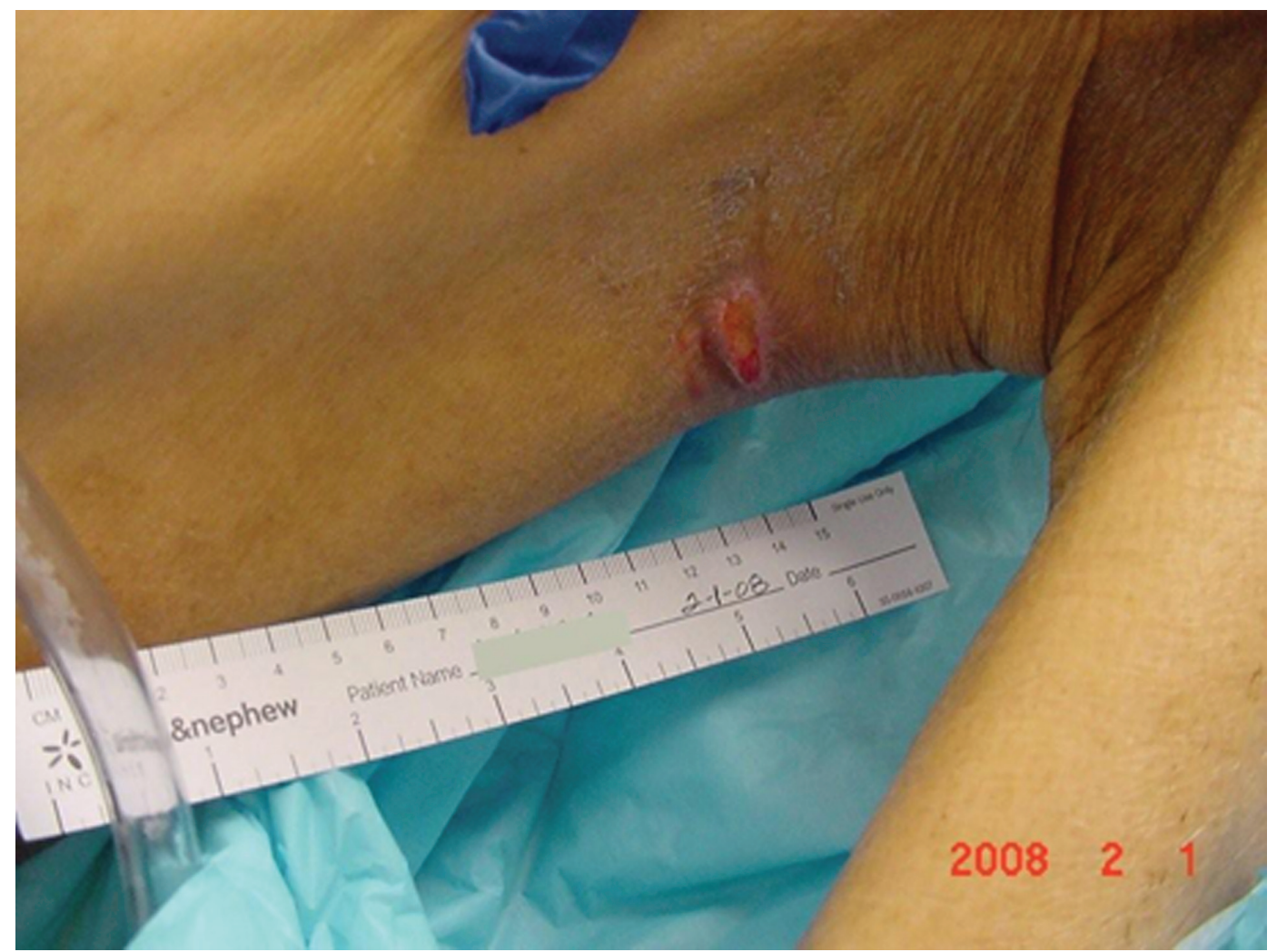

Figure 5 Posterior right thigh, Stage III. 


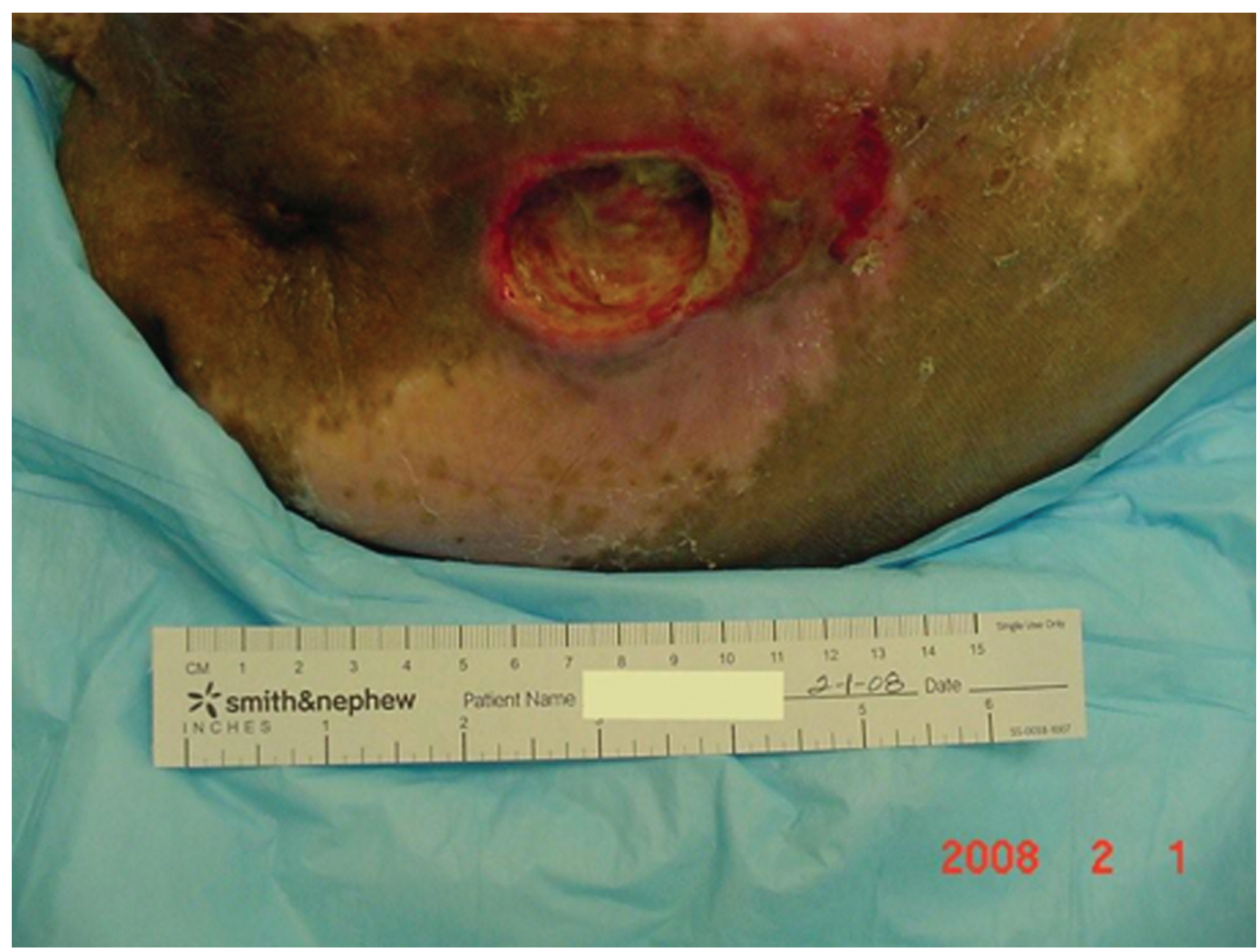

Figure 6 Coccyx, Stage IV.

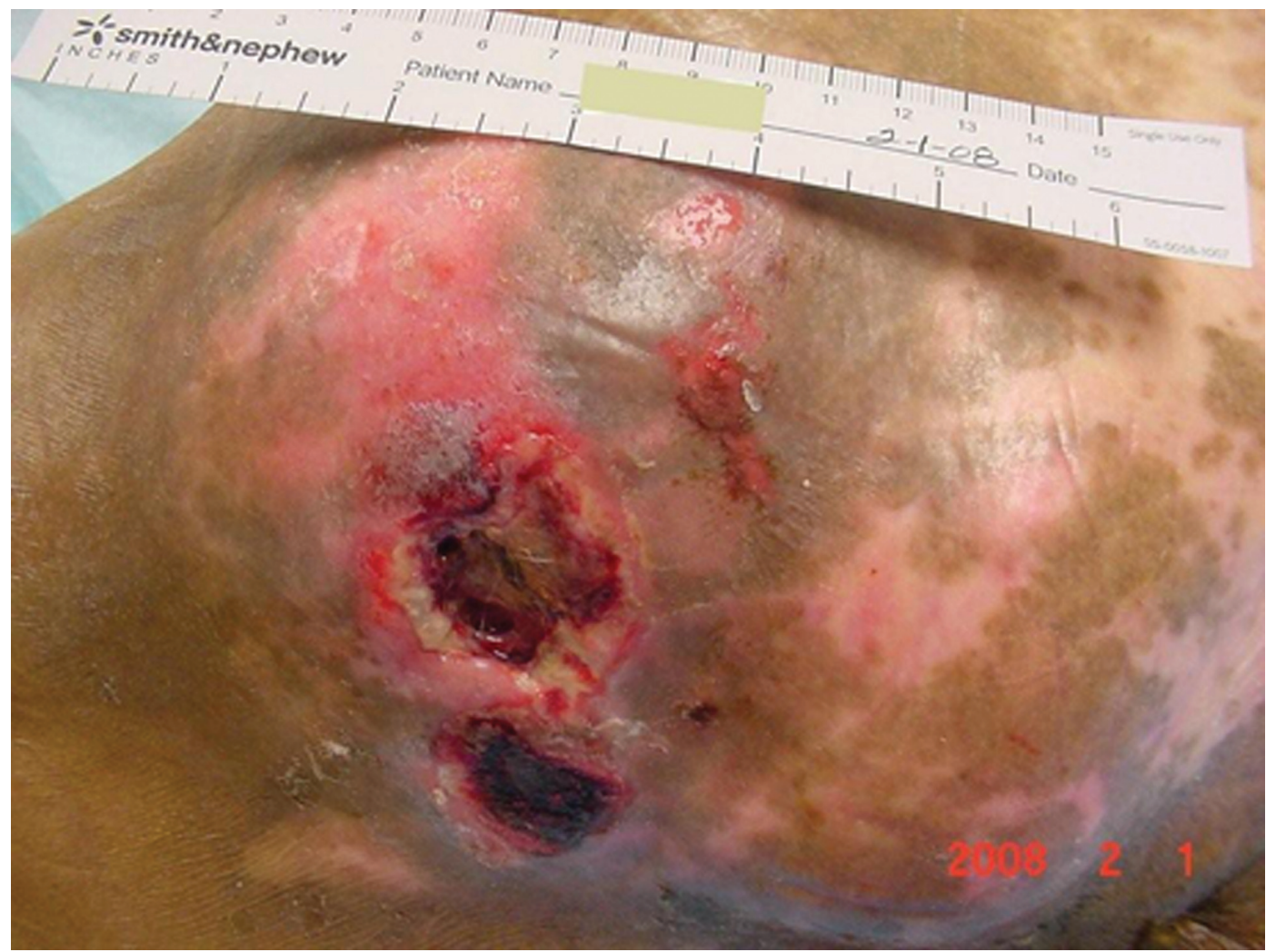

Figure 7 Left hip, Stage IV; unstageable eschar covered. 


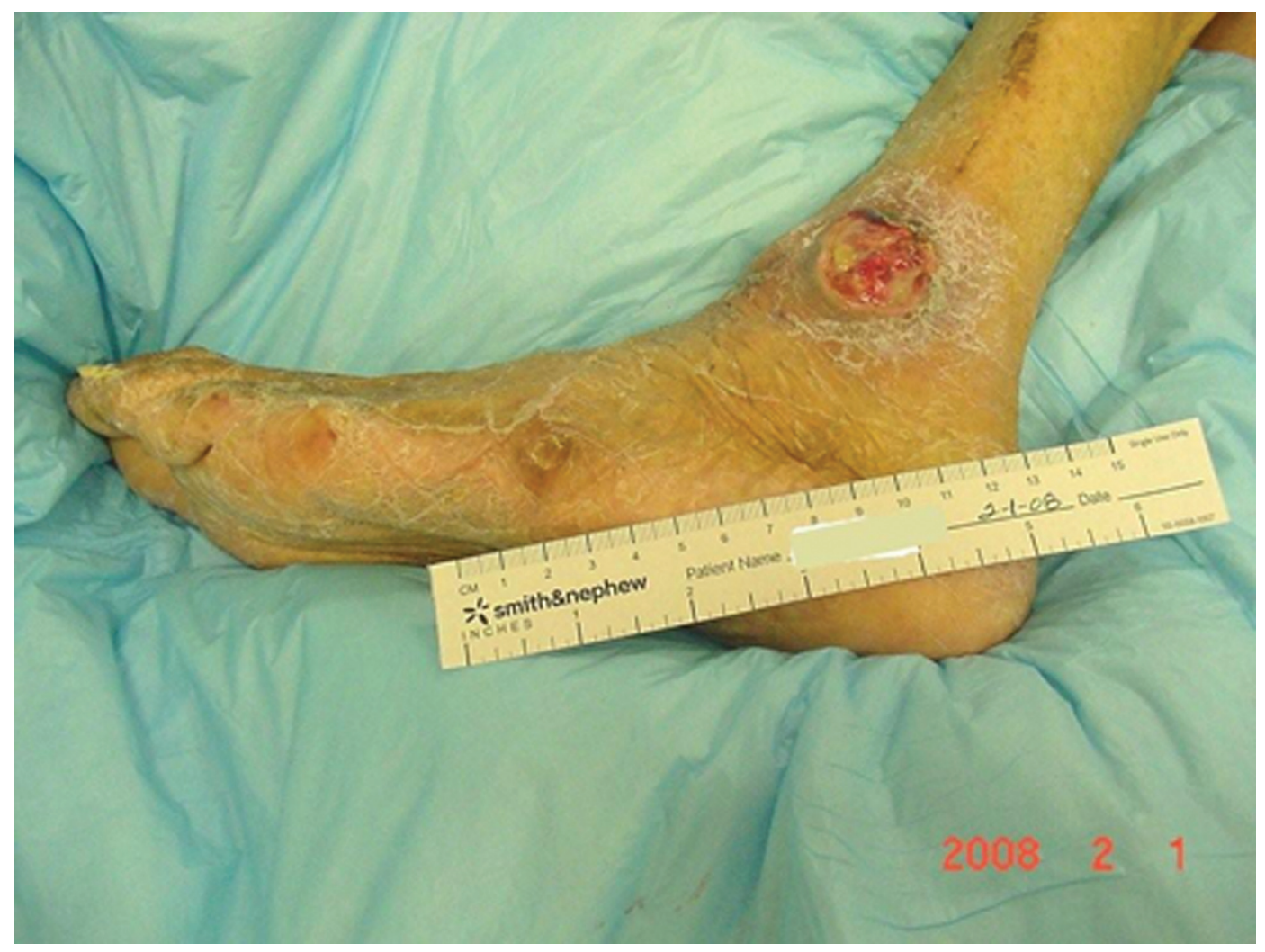

Figure 8 Lateral left ankle, Stage IV; lateral mid-foot, unstageable.

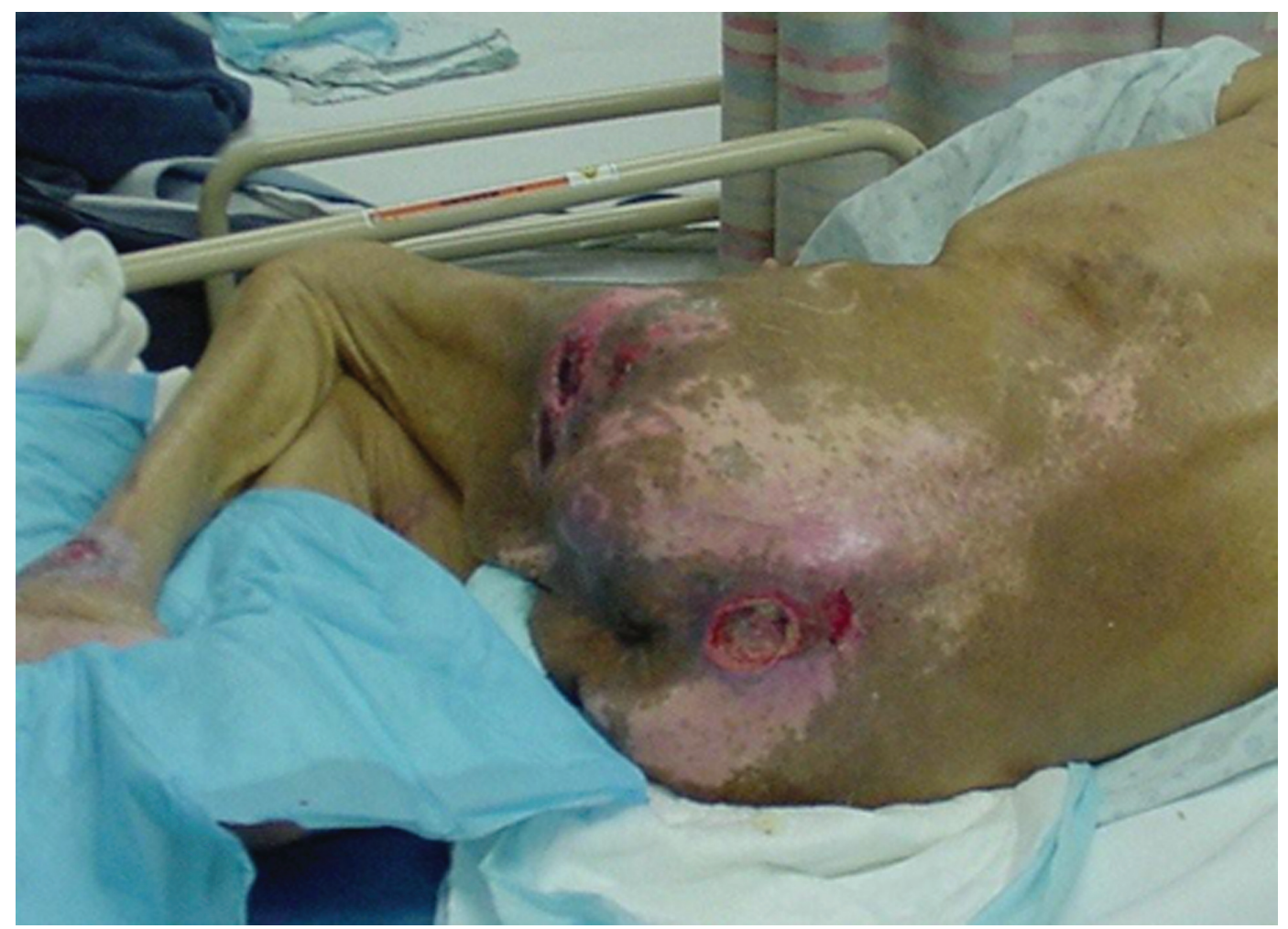

Figure 9 Full body view, multiple ulcers. 
Mr WC had not been wearing the protective devices at night and the ulcers worsened. The right heel ulcer measured $6.5 \mathrm{~cm} \times 5.5 \mathrm{~cm}$ with large amount yellow slough in center of the wound. Conservative sharp debridement was completed to decrease necrotic tissue and reduce bioburden. The left heel ulcer was clean, the wound base, a combination of slough and granulation tissue, measured $1.2 \mathrm{~cm} \times 1.7 \mathrm{~cm}$. The lesions were irrigated with NS and the initial dressing options were continued. At this time it was decided to begin negative pressure wound therapy to the right heel ulcer.

A VAC Freedom (Kinetic Concepts, Inc.) was applied with the unit set at $125 \mathrm{mmHg}$ continuous negative pressure. In two weeks, the right heel ulcer measured $6.0 \mathrm{~cm} \times 5.0 \mathrm{~cm}$, the wound base was $80 \%$ granulation and $20 \%$ slough. The left heel ulcer measured $1.0 \mathrm{~cm}$ in diameter. Two weeks later, the right heel ulcer measured $5.5 \mathrm{~cm} \times 4.5 \mathrm{~cm} \times 1.0 \mathrm{~cm}$, did not probe to bone and the wound base was fully granulated.
The VAC dressing was discontinued and a foam dressing was applied with a light compression wrap to secure it. The foam dressing provided absorption and cushioning of the wound, compression controlled edema.

With the improvement in the wound, the decision was made to apply Dermagraft dressings to facilitate wound closure. Dermagraft was applied once a week for five weeks with continued attention to the control of exudate and edema. The ulcer on the left heel progressed to complete closure with conservative dressing applications and continued pressure relief. The right heel also progressed to complete closure with application of Dermagraft combined with other conservative dressing techniques to control for infection through use of topical antimicrobials (silver alginates, Iodosorb gel), exudate management (foam and composite dressings) and edema reduction with light compression wraps. Knee high compression stockings (20-30 $\mathrm{mmHg}$ ) were used after healing was complete (Figures 10-12).

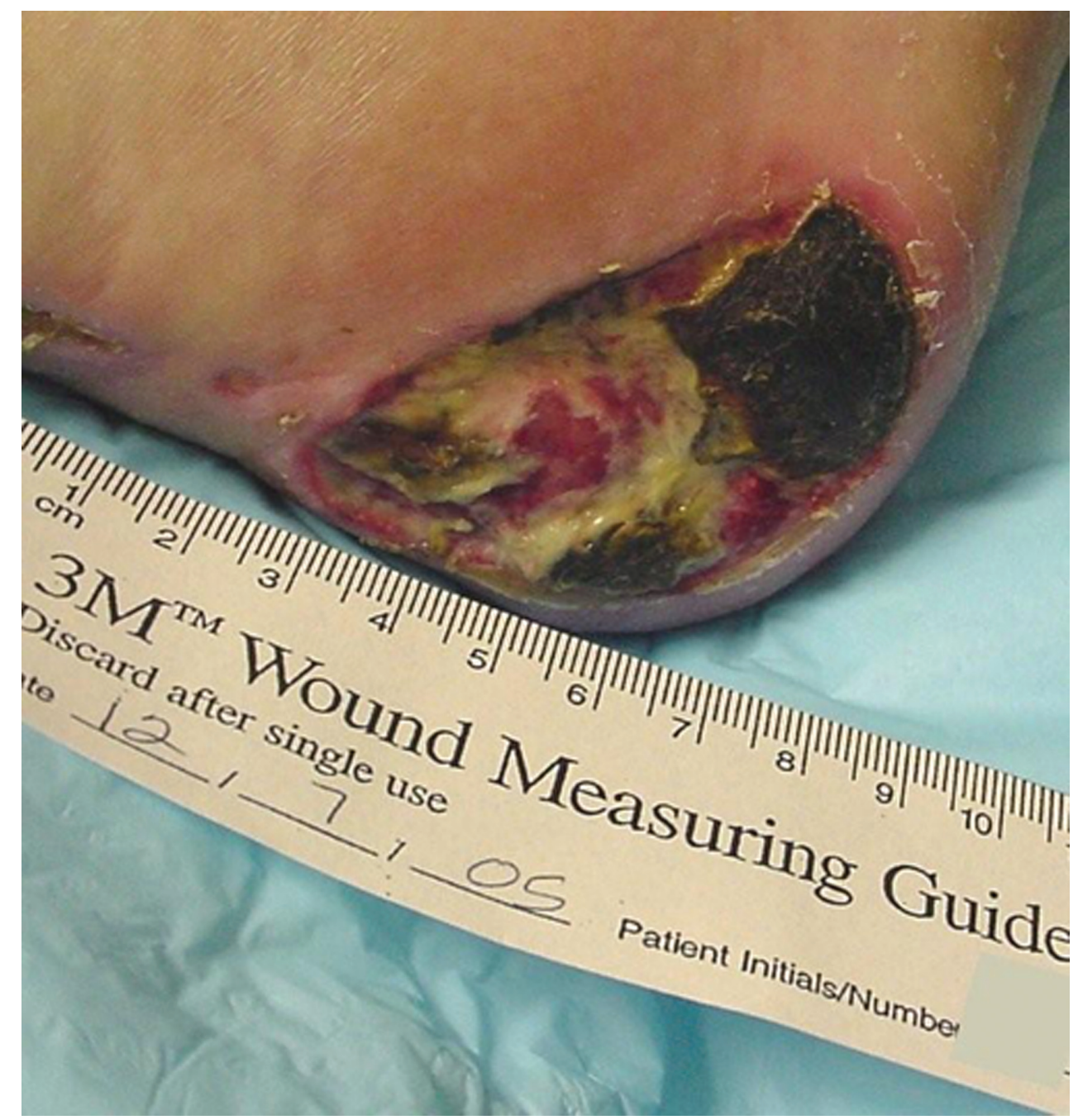

Figure I0 Right posterior heel, Stage IV, with slough and eschar. 


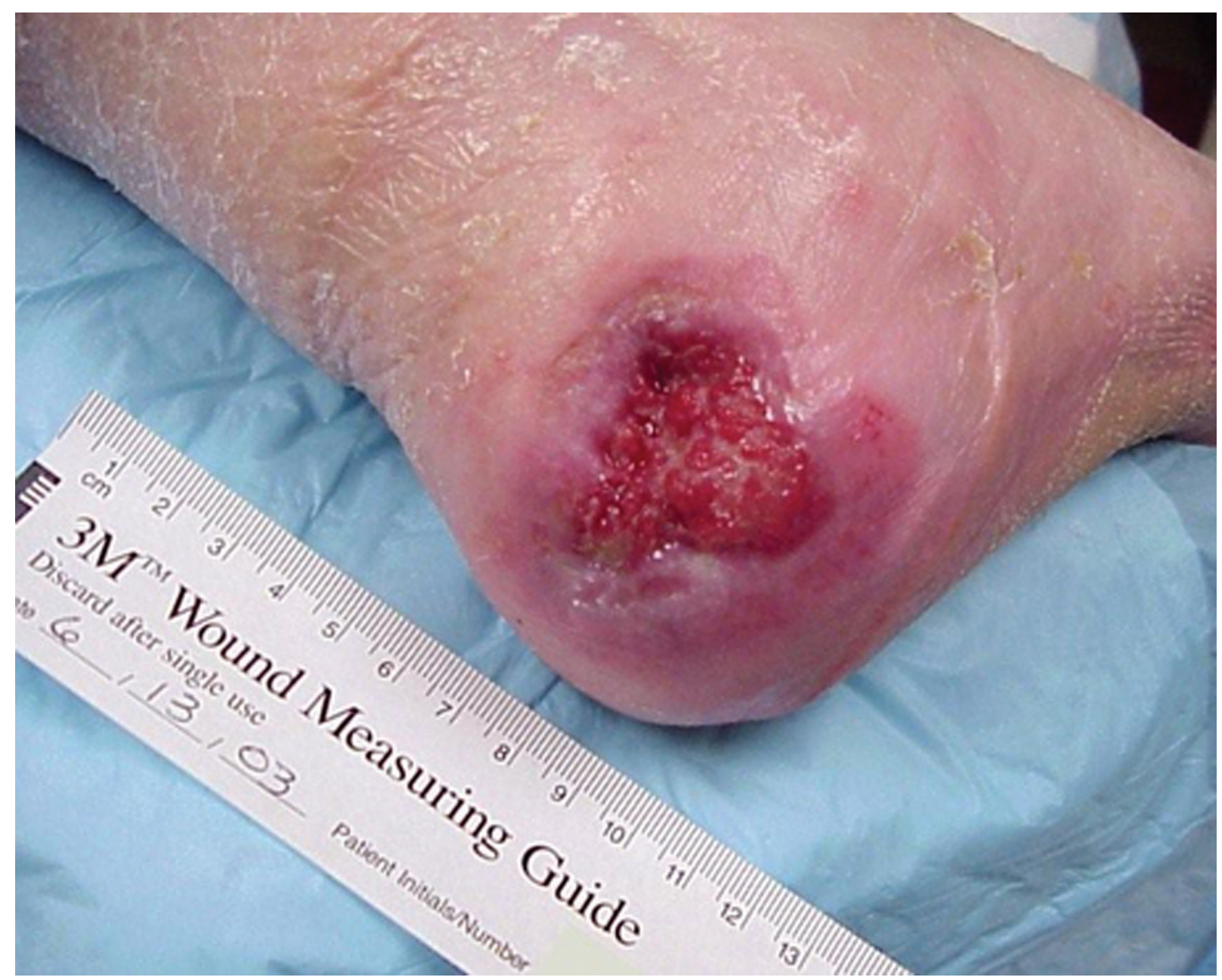

Figure I I Right posterior heel with granulation tissue.

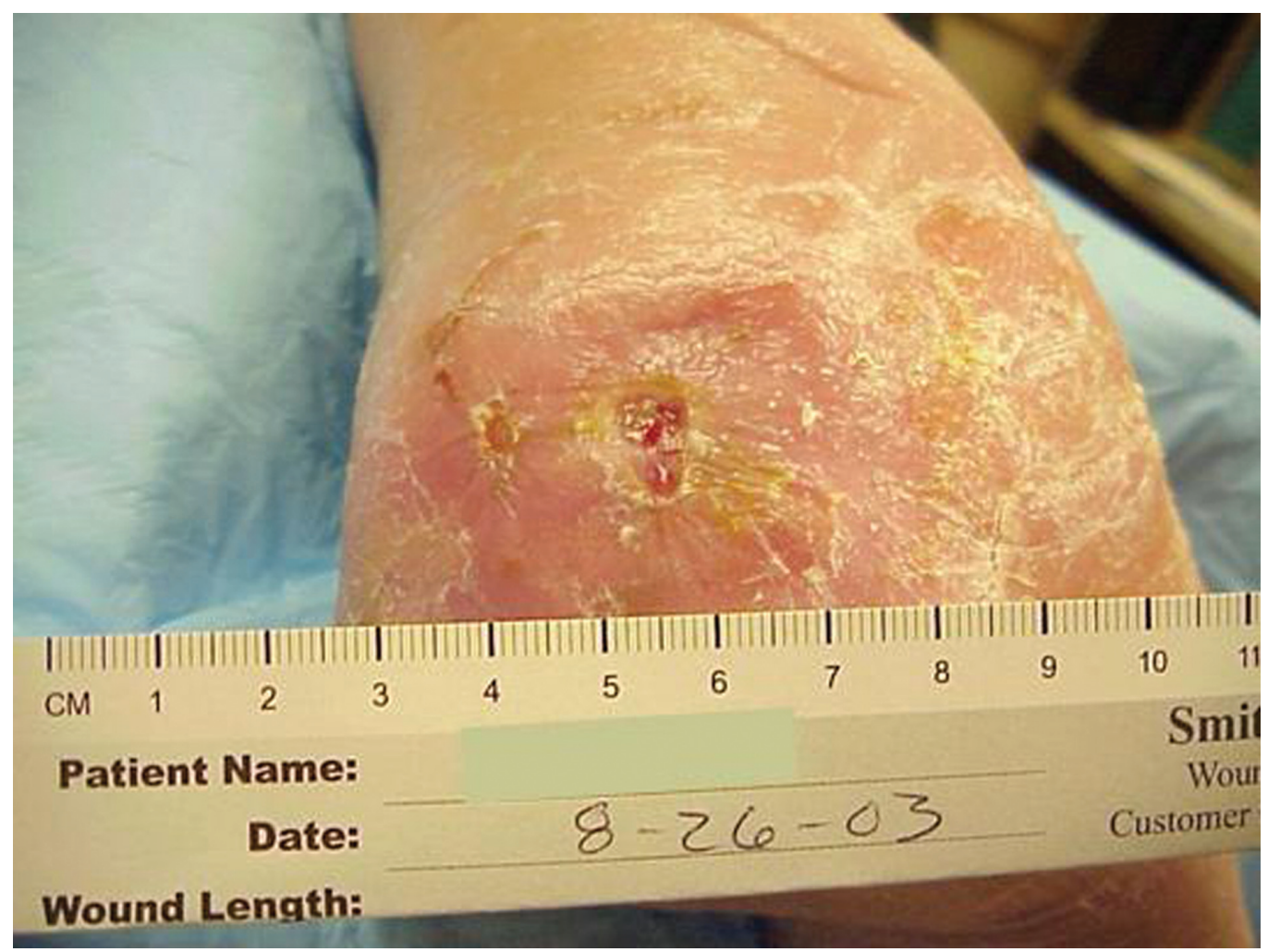

Figure 12 Right posterior heel almost healed. 


\section{Disclosure}

The authors report no conflicts of interest in this work.

\section{References}

1. Thomas DR. Issues and dilemmas in prevention and treatment of pressure ulcers: a review. J Gerontol. 2001;56A:M328-M340.

2. Stotts N, Hopf H. Facilitating positive outcomes in older adults with wounds. Nurs Clin North Am. 2005;40:267-279.

3. Langemo DK, Brown G. Skin fails too: acute, chronic, and end-stage skin failure. Adv Skin Wound Care. 2006;19:206-211

4. Shea JD. Pressure sores classification and management. Clin Orthop Relat Res. 1975;112:89-100.

5. Black J, Baharestani M, Cuddigan J, et al; National Pressure Ulcer Advisory Panel. National Pressure Ulcer Advisory Panel's updated pressure ulcer staging system. Dermatol Nurs. 2007;19:343-349.

6. Medscape. National Pressure Ulcer Advisory Panel's updated ulcer staging system. 2007. [Cited Nov 13, 2007]. Available from: http:// www.medscape.com/.

7. Fleck C. Suspected deep tissue injury. Adv Skin Wound Care. 2007;20:413-415.

8. Keast DH, Parslow N, Houghton PE, Norton L, Fraser C. Best practice recommendations for the prevention and treatment of pressure ulcers: update 2006. Adv Skin Wound Care. 2007;20:447-460; quiz 461-462.

9. Gray M. Preventing and managing perineal dermatitis: a shared goal for wound and continence care. J Wound Ostomy Continence Nurs. 2004;31(1 Suppl):2-9.

10. Thompson P, Langemo D, Anderson J, et al. Skin care protocols for pressure ulcers and incontinence in long term care: a quasi- experimental study. Adv Skin Wound Care. 2005;18:422-429.

11. Bourdel-Marchasson I, Barateau M, Rondeau V, et al. A multi-center trial of the effects of oral nutritional supplementation in critically ill older inpatients. Nutrition. 2000;16:1-5.

12. Paquette D, Falanga V. Leg ulcers. Clinics Geri Med. 2002;18:77-88.

13. Wipke-Tevis DD, Sae-Sia W. Management of vascular leg ulcers. $A d v$ Skin Wound Care. 2005;18:437-445.

14. Aronow WS. Peripheral arterial disease. Geriatrics. 2007;62:19-25.

15. Holman JR. Peripheal arterial disease: tips on diagnosis and management. Consultant. 2004;14:101-108.

16. Sibbald RG, Williamson D, Orsted HL, et al. Preparing the wound bed-debridement, bacterial balance, and moisture balance. Ostomy Wound Manage. 2000;46:14-22, 24-28, 30-35; quiz 36-37.

17. Kirshen C, Woo K, Ayello EA, et al. Debridement: a vital component of wound bed preparation. Adv Skin Wound Care. 2006;19:506-517.

18. Gunder DV, Kaufman MW, Gustafan N. Patient with chronic venous stasis ulcer. J Wound Ostomy Continence Nurs. 2003;30:53-58.

19. Brill LR, Stone JA. New treatments for lower extremity ulcers. Patient Care for the Nurse Practitioner. 2001;12:9-20.

20. Hunter S, Langemo D, Hanson D, et al. Compression therapy of venous ulcers. Adv Skin Wound Care. 2005;18:404-408.
21. Kravitz SR, McGuire JB, Sharma S. The treatment of diabetic foot ulcers: Reviewing the literature and a surgical algorithm. Adv Skin Wound Care. 2007;20:227-237.

22. Edmonds M. A natural history and framework for managing diabetic foot ulcers. Br J Nurs. 2008;17:S20, S22, S24-S29.

23. Mulder GD, Armstrong DG. Management of the diabetic foot ulcer in the elderly population. Clin Geriatrics. 2003;11:46-53.

24. Inlow S, Orsted H, Sibbald RG. Best practices for the prevention, diagnosis and treatment of diabetic foot ulcers. Ostomy Wound Manage. 2000;46:55-68.

25. Johnsen B. Acute Charcot's arthropathy: A difficult diagnosis. JAAPA 2007;20:22-26.

26. Centers for Disease Control and Prevention. National Diabetes Fact Sheet: General information and national estimates on diabetes in the United States, 2005. Atlanta, GA: US Department of Health and Human Services, Centers for Disease Control and Prevention; 2005.

27. US Food and Drug Administration. Communication about an ongoing safety review, Regranex (Becaplermin). 2008. [Cited Mar 28, 2008]. Available from: http://www.fda.gov/medwatch/report.htm.

28. Schultz GS, Sibbald RG, Falanga V, et al. Wound bed preparation: a systemic approach to wound management. Wound Repair Regen, 2003;11(Supp1 1):S1-S28.

29. Medina A, Scott PG, Ghahary A, et al. Pathophysiology of chronic nonhealing wounds. J Burn Care Rehabil. 2005;26:306-319.

30. Dere K, Opkaku A, Golden A, et al. The 21 st century treatment of venous stasis ulcers. Long-Term Care Interface. 2006;34-37.

31. Woo K, Ayello EA, Sibbald RG. The edge effect: current therapeutic options to advance the wound edge. Adv Skin Wound Care. 2007;20:99-117.

32. Bowler PG, Duerden BI, Armstrong DG. Wound microbiology and associated approaches to wound management. Clin Microbiol Rev. 2001;14:244-269.

33. Hermans MH. Silver-containing dressings and the need for evidence. Adv Skin Wound Care. 2007;20:166-173.

34. Beitz JM. Wound debridement: therapeutic options and care consideration. Nurs Clinic North Am. 2005;40:233-249.

35. Courtney M, Church JC, Ryan TJ. Larva therapy in wound management, $J R$ Soc Med. 2000;93:72-74.

36. Okan D, Woo K, Ayello EA, et al. The role of moisture balance in wound healing. Adv Skin Wound Care. 2007;20:39-53.

37. Turner TD. Hospital usage of absorbent dressings. Pharma J. 1979;222:421-426.

38. Brett DW. A review of moisture-control dressings in wound care. J Wound Ostomy Continence Nurs. 2006;33(6 Suppl):53-58.

39. Fletcher J. Understanding wound dressings: Alginate. Nursing Times. 2005;101:16:53-54.

40. Nursing Times. Alginate dressings. Nursing Times. 2005;101:28:31.

41. Aparicio Gallego E, Castilla Peris C, Diez Garcia MT, et al. [Therapeutic behavior of a hydrocolloid dressing. Its evolution in the treatment of acute and chronic dermal ulcers]. Rev Enferm. 2005;28(12):49-55.

42. Takahashi P, Chandra A, Kiemele L, Targonski P. Wound care technologies: emerging evidence for appropriate use in long-term care. Annals of Long-Term Care. 2007;15:35-40.
Clinical Interventions in Aging

\section{Publish your work in this journal}

Clinical Interventions in Aging is an international, peer-reviewed journal focusing on evidence-based reports on the value or lack thereof of treatments intended to prevent or delay the onset of maladaptive correlates of aging in human beings. This journal is indexed on PubMed Central, MedLine, the American Chemical Society's 'Chemical

\section{Dovepress}

Abstracts Service' (CAS), Scopus and the Elsevier Bibliographic databases. The manuscript management system is completely online and includes a very quick and fair peer-review system, which is all easy to use. Visit http://www.dovepress.com/testimonials.php to read real quotes from published authors. 